\title{
Electrolytic Polishing of Cold Worked Zr-2.5Nb for the Examination of Zr- Hydrides
}

\author{
A.J. Lockley
}

Materials \& Mechanics, AECL, Chalk River Laboratories, Chalk River, ON, K0J 1J0

Electrolytic polishing methods have been developed for the metallographic preparation of zirconium alloys [1][2]. Although mostly used to develop general microstructure, electrolytic polishing is also useful for the examination of Zr-hydrides. Hydrogen readily dissolves into zirconium at elevated temperatures however, during cooling, the hydrogen comes out of solution and precipitates as $\mathrm{Zr}$ hydrides. Zr-Hydrides are brittle and can cause cracking by a phenomenon referred to as delayedhydride cracking (DHC). Traditional methods of metallography used for the examination of Zrhydrides include grinding, rough polishing and finish using an attack polish [3][4]. Zr-Hydrides are then revealed using a swab-etching technique (Figure 1). This method, although sufficient to assess $\mathrm{Zr}$-Hydrides using optical microscopy, is undesirable at the higher magnifications attainable using scanning electron microscopy because etching destroys detail associated with Zr-Hydrides. However, Zr-Hydrides in specimens prepared using electrolytic polishing retain a notable amount of detail.

Specimens were electrolytically polished using a commercially available polishing apparatus that provides voltage and duration control, tank agitation, electrolyte bath cooling, and temperature monitoring. Using an electrolyte maintained at a temperature between $-50^{\circ} \mathrm{C}$ and $-60^{\circ} \mathrm{C}$, using liquid nitrogen, several different combinations of current density and polishing duration were used to achieve an optimal microstructure that best revealed Zr-Hydrides.

Prepared specimens were examined in a JEOL 840 SEM using both Secondary Electron imaging (SE) and Back Scatter Electron imaging (BSE). Prepared surfaces were examined in the as-etched condition and also with a gold sputtered coated layer. A region in each specimen was imaged in SE, $\mathrm{BSE}$, and SE after sputter coating for comparison purposes.

A comparison of a Zr-hydride using SE and BSE imaging is shown in Figure 2. SE imaging provided microstructure detail of $\alpha-\mathrm{Zr}$, the $\beta$-phase as well as $\mathrm{Zr}$-hydrides. This is particularly noticeable in the prominence of $\beta$-phase as well as the sharp distinction between $Z r$-hydrides and the $\alpha-Z r / \beta$-phase matrix. BSE imaging provided good contrast between $\mathrm{Zr}$-hydrides and the $\alpha-\mathrm{Zr} / \beta$-phase matrix. Although BSE images are not as sharp as SE images, the Zr-hydrides are better contrasted against the $\alpha-\mathrm{Zr} / \beta$-phase matrix. This is especially advantageous if the $\mathrm{Zr}$-hydrides are to be quantified by some means such as an image analyzer. Gold sputter coating did not provide any advantage in imaging.

[1] P.E. Danielson, Zirconium and Hafnium and Their alloys, Metals Handbook, Ninth Edition, Volume 9, ASM International, 1986.

[2] A.J. Lockley, Metallographic Preparation of Zr-2.5Nb Pressure Tube Material for Examination of Inclusions, Microstructural Science Volume 22, ASM International, 1995.

[3] Grain Size Determination in Zirconium Alloys, IAEA-TECDOC-794, IAEA, 1995.

[4] G. Petzow, Metallographic Etching, 2nd ed, ASM International, 1999.

Thanks to M. Seguin and A. Gin for micrographs. 


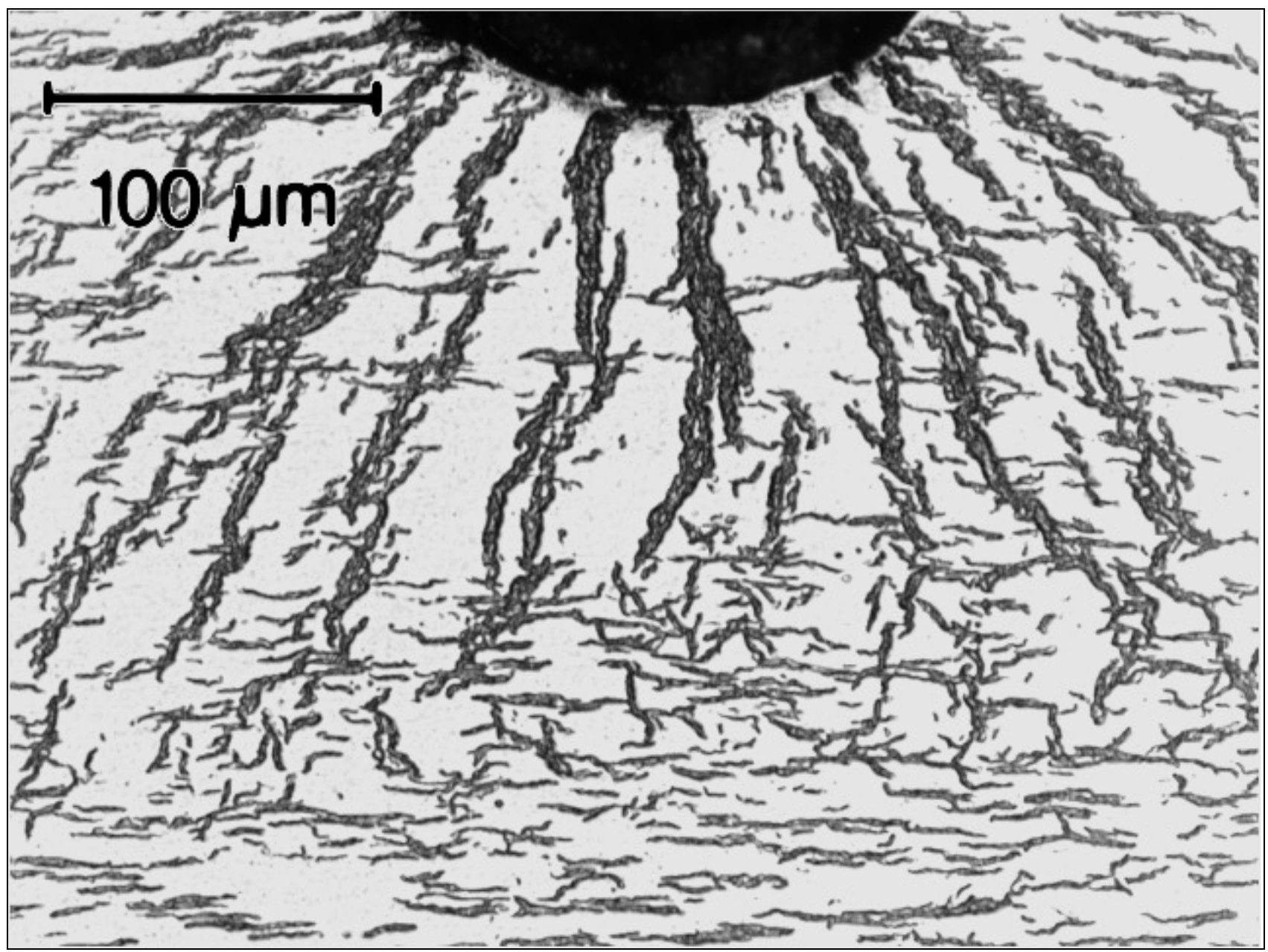

Figure 1: Optical micrograph of Zr-hydrides (dark linear features) in $\mathrm{Zr}-2.5 \mathrm{Nb}$ revealed using a swab etching technique.

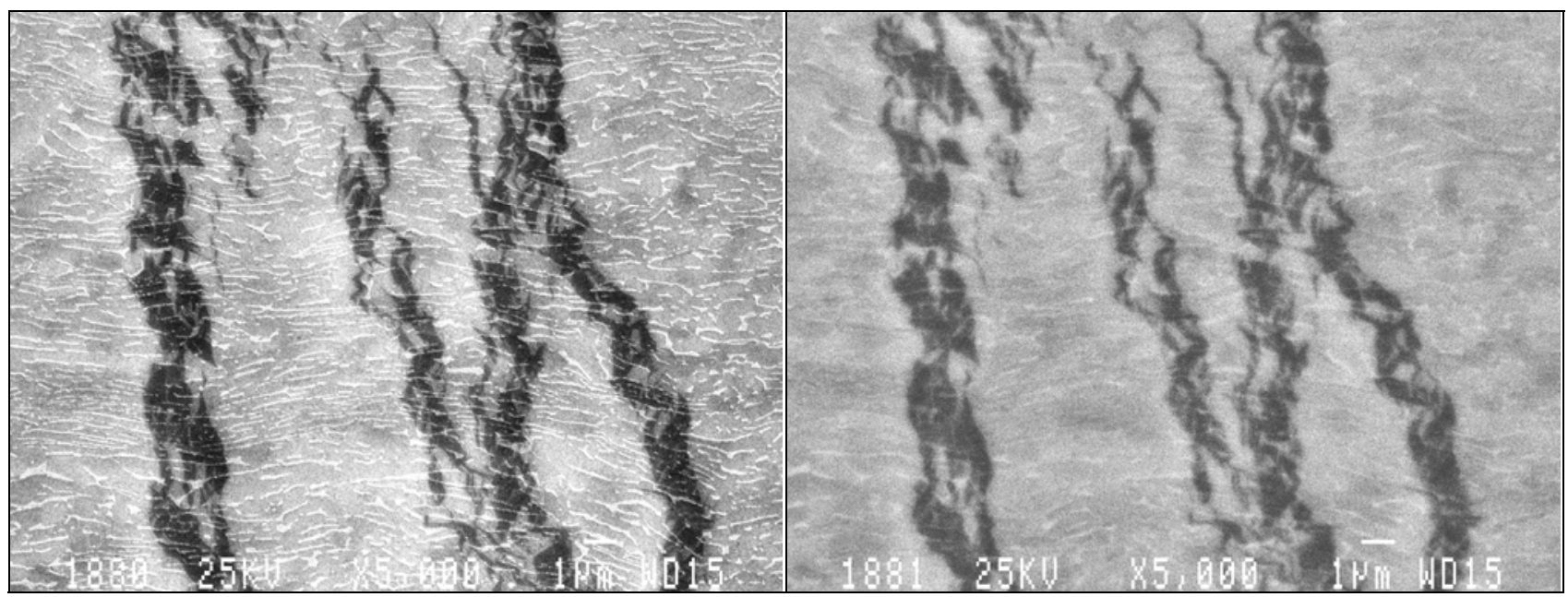

Figure 2: A comparison of SE (a) and BSE (b) micrographs of a $\mathrm{Zr}$-hydride in $\mathrm{Zr}-2.5 \mathrm{Nb}$ prepared using electrolytic polishing. Zr-hydrides are dark regions in both images. The white features in the SE image (a) are $\beta$-phase and are less visible in BSE (b). 